\title{
Cluster Structure of Imidazolium Salts in Methanol Controlled by the Balance of Interactions: Cation-Anion, Cation-Solvent, and Anion-Solvent
}

\author{
Satoshi Kitaoka, * Kaoru Nobuoka,* Yuichi IshiKawa,* and Akihiro WaKisaKa**† \\ *Department of Applied Chemistry, Faculty of Engineering, Oita University, 700 Dannoharu, Oita 870-1192, Japan \\ **National Institute of Advanced Industrial Science and Technology (AIST), \\ 16-1 Onogawa, Tsukuba, Ibaraki 305-8569, Japan
}

\begin{abstract}
We have studied the cluster structure of 1-butyl-3-methylimidazolium halide, bmimX $(\mathrm{X}=\mathrm{Cl}, \mathrm{Br}$, I), in methanol solution by means of an electrospray mass spectrometer, which is specially designed for analysis of clusters isolated from solution. In positive ion mode experiments, the ratio of solvated bmim $^{+}$, bmim $^{+}(\mathrm{MeOH})_{\mathrm{n}}$ and ion-pair clusters, bmim $\left(\mathrm{bmim}^{+} \mathrm{X}^{-}\right)_{\mathrm{m}}$ was dependent on the counter anion. As for bmimCl solutions, few solvated bmim ${ }^{+}$clusters were observed, and the ionpair clusters were clearly observed. On the other hand, bmimBr and bmimI with large anions, the solvated bmim $^{+}$clusters increased obviously, and the ion-pair clusters were in turn remarkably decreased. In negative ion-mode experiments, the solvation for $\mathrm{Br}^{-}$by the methanol is found to be the most prominent among those for $\mathrm{Cl}^{-}, \mathrm{Br}^{-}$, and $\mathrm{I}^{-}$. These results were reasonably explained in consideration of the balance between ion-solvent and ion-counterion interactions.
\end{abstract}

(Received March 21, 2008; Accepted May 13, 2008; Published October 10, 2008)

\section{Introduction}

The imidazolium salts (Fig. 1) are representative salts as ionic liquids. These salts can liquefy below room temperature in dependence on the counter anion, even though they are composed only of ions. For 1-butyl-3-methylimidazolium halides (bmimX: $\mathrm{X}=\mathrm{Cl}, \mathrm{Br}, \mathrm{I}$ ), the structures in the liquid and in the crystal have been studied in detail. It was shown that the presence of two crystalline polymorphs for $\mathrm{bmimCl}^{1}$ and the existence of two conformers of $\mathrm{bmim}^{+}$for $\mathrm{bmimI}^{2}$ were related to their low melting points. Furthermore, the cation-anion interaction of the imidazolium salt has been extensively studied by X-ray diffraction, ${ }^{1-3} \mathrm{NMR},{ }^{4}$ electrochemical studies, ${ }^{5}$ neutron diffraction, ${ }^{6}$ and ESI-MS. ${ }^{7-11}$ These studies analyzed the ionic liquid itself, and have showed the physical properties of ionic liquids. In addition, imidazolium type ionic liquids are used as reaction media or catalyst ${ }^{12}$ for Diels-Alder reaction, ${ }^{13-15}$ Fischer esterification, ${ }^{16}$ and Suzuki cross-coupling reaction. ${ }^{17,18}$ Since these reactions were carried out in mixtures of the ionic liquid and the substrate, the microscopic structure in the solution is also important to understand the role of imidazolium salts.

Here we would like to focus specially on the cluster structures of 1-butyl-3-methylimidazolium halides (bmimX) with $\mathrm{X}=\mathrm{Cl}$, $\mathrm{Br}$, and I dissolved in methanol. To discuss physicochemical properties of bmimX as an electrolyte, the cluster structures of bmimX in methanol were compared with those of $\mathrm{NaCl}$ in methanol through their mass spectrometric analyses. The electrospray mass spectrometry (ES-MS) has been applied to analysis for ionic liquids. ${ }^{7-11}$ Neat or diluted ionic liquids were analyzed by the ES-MS, and formation of ion-pairs was

† To whom correspondence should be addressed.

E-mail: akihiro-wakisaka@aist.go.jp observed as depending on the ion-counterion interaction energies. However, it has been difficult to observe ionic liquidsolvent interactions, since the ion-solvent interaction energy is lower than the ion-counterion interaction energies.

We have designed an electrospray mass spectrometer specially to observe clusters reflecting ion-solvent interactions in solution. ${ }^{19,20}$ Clusters generated through fragmentation of liquid droplets could be measured. By using this mass spectrometry, we have reported the cluster structures of lithium halides (LiX: $\mathrm{LiCl}, \mathrm{LiBr}, \mathrm{LiI})$ in methanol. ${ }^{21}$ Interestingly, the number of solvated methanol molecules in the clusters $\mathrm{Li}^{+}\left(\mathrm{Li}^{+} \mathrm{X}^{-}\right)_{\mathrm{m}}(\mathrm{MeOH})_{\mathrm{n}}$ observed through the mass spectrometry was strongly influenced by the $\mathrm{Li}^{+}-\mathrm{X}^{-}$interaction. With a decrease of the $\mathrm{Li}^{+}-\mathrm{X}^{-}$ interaction energy from $\mathrm{X}^{-}=\mathrm{Cl}^{-}$to $\mathrm{I}^{-}$, the number of methanol molecules $(n)$ in $\mathrm{Li}^{+}\left(\mathrm{Li}^{+} \mathrm{X}^{-}\right)_{\mathrm{m}}(\mathrm{MeOH})_{\mathrm{n}}$ increased remarkably. This suggested the "complementary relationship" between $\mathrm{Li}^{+}-\mathrm{MeOH}$ and $\mathrm{Li}^{+}-\mathrm{X}^{-}$interaction. The clusters were formed through the balance of interactions between $\mathrm{Li}^{+}-\mathrm{MeOH}$ and $\mathrm{Li}^{+}-\mathrm{X}^{-}$in the condensed phase. ${ }^{21,22}$ Although bmim ${ }^{+}$looks quite different from $\mathrm{Li}^{+}$, there is one common physicochemical property as an electrolyte in solution that their clustering in solution is controlled by the balance of interactions between ion-solvent and ion-counterion.

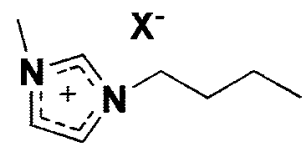

\section{$\operatorname{bmim} X(X=\mathrm{Cl}, \mathrm{Br}, \mathrm{l})$}

Fig. 1 The structure of bmim salts. 


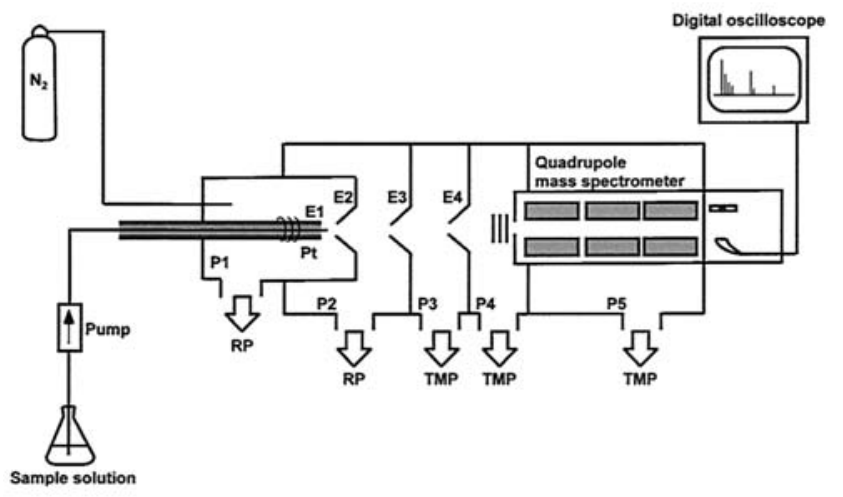

Fig. 2 Schematic picture of a mass spectrometer specially designed for the analysis of clusters. $E$ and $P$ denote electric potential and pressure, respectively. Pt represents a platinum electrode to supply the electric potential $E_{1}$. RP and TMP correspond to rotary pump and turbo molecular pump, respectively. The positively or negatively multi-charged liquid droplets were generated between the nozzle and the first skimmer.

\section{Experimental}

\section{Chemicals}

All chemicals were purchased from commercial sources (Wako or Aldrich) and used without further purification. All ionic liquids used here were prepared according to the reported procedures $^{23,24}$ and vacuum-dried $\left(10.3 \mathrm{~Pa}, 60^{\circ} \mathrm{C}, 24 \mathrm{~h}\right)$.

\section{Mass spectrometry}

To obtain information on the microscopic structures in solutions, we measured the mass spectra of clusters isolated through fragmentation of liquid droplets by the specially designed mass spectrometry. ${ }^{19-22}$ As shown in Fig. 2 schematically, the mass spectrometer is composed of a fivestage differentially pumped vacuum system, a homemade electrospray interface and a quadrupole mass filter (Extral C50). For the electrospray, electric voltages were supplied to the nozzle and to three skimmers $\left(E_{1}-E_{4}\right)$, and nitrogen gas was flowing to maintain an appropriate pressure balance $\left(P_{1}-P_{5}\right)$. When an ionic solution was injected into the high electric field between the nozzle and the first skimmer through a fused silica capillary tube (i.d., $0.1 \mathrm{~mm}$ ) at a flow rate $0.03 \mathrm{~cm}^{3} / \mathrm{min}$, positively or negatively multi-charged liquid droplets including excess cations or anions were generated according to the polarity of the electric field through the electrospray principle. The resulting multi-charged liquid droplets were fragmented into clusters via adiabatic expansion and electrostatic repulsion during the flight. The clusters charged by the included ions were analyzed by the quadrupole mass filter without using any external ionization. By measuring both positively and negatively charged clusters, we obtained results based on which the microscopic structures in electrolyte solutions could be discussed more precisely. The typical conditions for the electric potentials $\left(E_{1}-E_{4}\right)$ and the pressure balance $\left(P_{1}-P_{5}\right)$ were as follows: (i) positive ion mode: $\left(E_{1}, E_{2}, E_{3}, E_{4}\right)=(+2.90 \mathrm{kV},+212$ $\mathrm{V},+224 \mathrm{~V},+188 \mathrm{~V}),\left(P_{1}, P_{2}, P_{3}, P_{4}, P_{5}\right)=(85.7 \mathrm{kPa}, 1.27 \mathrm{kPa}$, $\left.1.07 \mathrm{~Pa}, 1.3 \times 10^{-3} \mathrm{~Pa}, 9.3 \times 10^{-5} \mathrm{~Pa}\right)$; (ii) negative ion mode: $\left(E_{1}-E_{4}\right)=(-2.56 \mathrm{kV},-224 \mathrm{~V},-227 \mathrm{~V},-186 \mathrm{~V}),\left(P_{1}-P_{5}\right)=$ $\left(97.2 \mathrm{kPa}, 1.73 \mathrm{kPa}, 1.73 \mathrm{~Pa}, 2.0 \times 10^{-3} \mathrm{~Pa}, 4.0 \times 10^{-4} \mathrm{~Pa}\right)$.

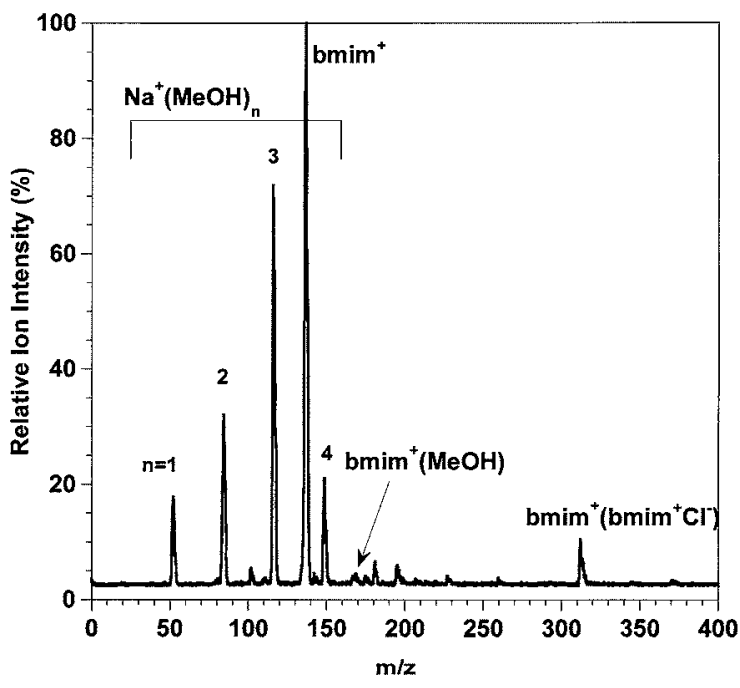

Fig. 3 Mass spectra of positively charged clusters isolated from methanol solutions including bmimCl $(5 \mathrm{mM})$ and $\mathrm{NaCl}(5 \mathrm{mM})$. Solvated $\mathrm{Na}^{+}, \mathrm{Na}^{+}(\mathrm{MeOH})_{\mathrm{n}}: n=1,2,3,4$; solvated $\mathrm{bmim}^{+}$, bmim $^{+}(\mathrm{MeOH})$; ion-pair cluster of bmim ${ }^{+}$salt, bmim $^{+}\left(\mathrm{bmim}^{+} \mathrm{Cl}^{-}\right)$.

\section{Results and Discussion}

\section{The comparison of bmim $\mathrm{Cl}$ and $\mathrm{NaCl}$ in methanol}

Figure 3 shows the mass spectra of positive ion clusters generated from methanol solutions including bmimCl $(5 \mathrm{mM})$ and $\mathrm{NaCl}(5 \mathrm{mM})$. Results clearly demonstrated that the behavior of bmim ${ }^{+}$in methanol shows a great contrast to that of $\mathrm{Na}^{+} . \mathrm{Na}^{+}$ ions exist mainly as solvated ions, $\mathrm{Na}^{+}(\mathrm{MeOH})_{n}: n=1-5$, and few naked $\mathrm{Na}^{+}$ions are observed. This indicates that $\mathrm{Na}^{+}$is solvated strongly. On the other hand, naked bmim $^{+}$is observed predominantly, and solvated $\mathrm{bmim}^{+}, \mathrm{bmim}^{+}(\mathrm{MeOH})$, is rarely observed. Instead, an ion-pair cluster, $\operatorname{bmim}^{+}\left(\mathrm{bmim}^{+} \mathrm{Cl}^{-}\right)$is observed. Since the charge density of bmim $^{+}$is much smaller than $\mathrm{Na}^{+}$, bmim ${ }^{+}$is not solvated as much as $\mathrm{Na}^{+}$is. From the peak-intensity ratio between $\operatorname{bmim}^{+}\left(\mathrm{bmim}^{+} \mathrm{Cl}^{-}\right)$and bmim $^{+}(\mathrm{MeOH})$ in Fig. 3, it is found that the formation of the ion-pair is more favorable rather than the solvation of $\mathrm{bmim}^{+}$for bmimCl in methanol. However, the ratio between the ion-pair cluster and the solvated bmim $^{+}$cluster formation was dependent on the balance of interactions between ion-solvent and ioncounterion, as observed for lithium halides in methanol. ${ }^{21}$

\section{The clusters of imidazolium halide}

In order to evaluate the effect of the balance of interactions between ion-solvent and ion-counterion, we compared the cluster structures of bmimCl, bmimBr, and bmimI in their methanol solutions. Figures $4 \mathrm{a}-4 \mathrm{c}$ show the mass spectra of positive ion clusters generated from these solutions including bmim $^{+}$salts $(5 \mathrm{mM})$ with halide anions: $\mathrm{Cl}^{-}, \mathrm{Br}^{-}$and $\mathrm{I}^{-}$, respectively. For bmimCl, the solvated $\mathrm{bmim}^{+}, \mathrm{bmim}^{+}(\mathrm{MeOH})$, is not easily observed (Fig. 4a), but the ion-pair clusters, bmim $^{+}\left(\text {bmim }^{+} \mathrm{Cl}^{-}\right)_{\mathrm{m}}: m=1-5$, are observed clearly. For bmimBr and bmimI with the bigger anions, the solvated bmim $^{+}$ cluster, $\operatorname{bmim}^{+}(\mathrm{MeOH})_{\mathrm{n}}: n=1-4$ increased considerably (Figs. $4 \mathrm{~b}$ and $4 \mathrm{c}$ ) in comparison with the case for bmimCl. The ionpair clusters interacting with $\mathrm{MeOH}, \mathrm{bmim}^{+}\left(\mathrm{bmim}^{+} \mathrm{X}^{-}\right)(\mathrm{MeOH})_{\mathrm{n}}$ : $n=1-2, \mathrm{X}=\mathrm{Br}$, I, were also observed, while the numbers of ion-pair clusters, $\mathrm{bmim}^{+}\left(\mathrm{bmim}^{+} \mathrm{X}^{-}\right)_{\mathrm{m}}$ : $\mathrm{X}=\mathrm{Br}$, I, were remarkably decreased. The $\operatorname{bmim}^{+}\left(\mathrm{bmim}^{+} \mathrm{X}^{-}\right)_{\mathrm{m}}$ with $m \geq 3$ are not formed for $\mathrm{X}=\mathrm{Br}$ and $\mathrm{I}$. 

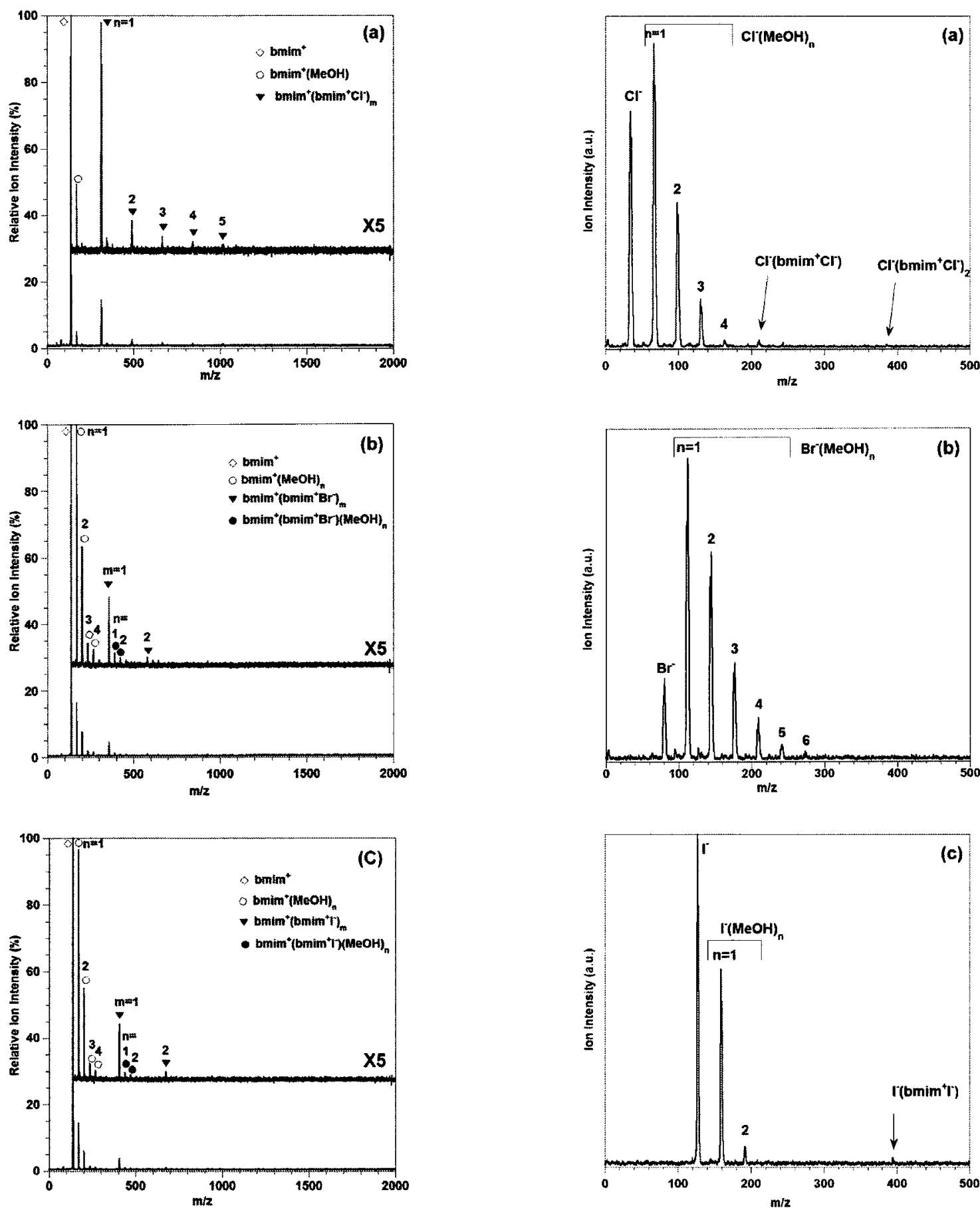

Fig. 4 Mass spectra of positively charged clusters isolated from methanol solutions including imidazolium halides $(5 \mathrm{mM})$. The observed clusters are solvated $\mathrm{bmim}^{+}, \mathrm{bmim}^{+}(\mathrm{MeOH})$; ion-pair clusters, $\operatorname{bmim}^{+}\left(\mathrm{bmim}^{+} \mathrm{X}^{-}\right)_{\mathrm{m}}$; and solvated ion-pair clusters, $\operatorname{bmim}^{+}\left(\mathrm{bmim}^{+} \mathrm{X}^{-}\right)(\mathrm{MeOH})_{\mathrm{n}}$. (a) bmimCl, (b) bmimBr, (c) bmimI.

\section{Solvation of halide ion}

To understand the effect of counter anion on the clustering, we measured the mass spectra of negatively charged clusters. Since the stability of negative ion clusters is sensitive to the electric potential for the electrospray, $E_{1}-E_{4}$ in Fig. 2, each measurement was carried out at similar conditions. In Fig. 5, the solvatedanions, $\mathrm{X}^{-}(\mathrm{MeOH})_{\mathrm{n}}: \mathrm{X}^{-}=\mathrm{Cl}^{-}, \mathrm{Br}^{-}, \mathrm{I}^{-}$, and the naked anion, $\mathrm{Cl}^{-}$, $\mathrm{Br}^{-}, \mathrm{I}^{-}$are observed. The solvation for $\mathrm{Br}^{-}$by the methanol is found to be the most prominent among those for $\mathrm{Cl}^{-}, \mathrm{Br}^{-}$and $\mathrm{I}^{-}$ This cannot be explained by the charge density of the anions,

Fig. 5 Mass spectra of negatively charged clusters isolated from methanol solutions including imidazolium halides $(5 \mathrm{mM})$. bmimCl, (b) bmimBr, (c) bmimI.

but can be reasonably explained in consideration with the balance between the anion- $\mathrm{MeOH}$ and the anion-bmim ${ }^{+}$ interaction, as shown in Fig. 6. Please note that the solvation for the anions is determined by the balance of interactions between anion-cation and anion-solvent. In the case of $\mathrm{Cl}^{-}$, the charge density is relatively high, which makes the interaction with bmim $^{+}$strong. Due to the complementary relationship between $\mathrm{Cl}^{-}-\mathrm{MeOH}$ and $\mathrm{Cl}^{-}$-bmim ${ }^{+}$interactions, the solvation for $\mathrm{Cl}^{-}$by $\mathrm{MeOH}$ would be reduced. In the case of $\mathrm{Br}^{-}$, the interaction with bmim $^{+}$is decreased. This would be complemented by the increase of solvation by $\mathrm{MeOH}$. For $\mathrm{I}^{-}$, the interaction with 
(a)

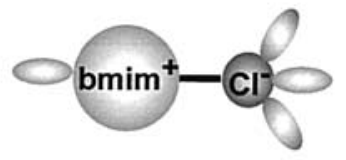

(b)

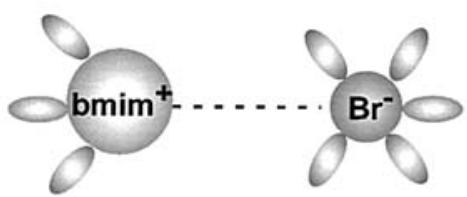

(c)

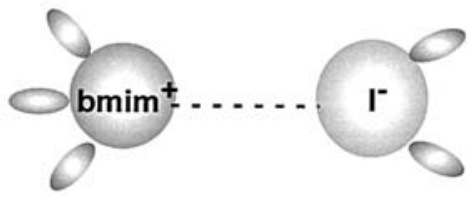

\section{[ $\bigcirc$ : solvating methanol ]}

Fig. 6 Schematic illustration for the possible interactions of bmimX in $\mathrm{MeOH}$. (a) bmimCl in $\mathrm{MeOH}$ : since the charge density of $\mathrm{Cl}^{-}$is relatively high, $\mathrm{Cl}^{-}-\mathrm{bmim}^{+}$interaction becomes dominant. (b) bmimBr in $\mathrm{MeOH}$ : the solvations for $\mathrm{Br}^{-}$and $\mathrm{bmim}^{+}$with $\mathrm{MeOH}$ are increased and the electrostatic interaction between bmim $^{+}$and $\mathrm{Br}^{-}$is decreased. (c) bmimI in $\mathrm{MeOH}$ : $\mathrm{I}^{-}$is difficult to combine the cation and the solvent, since the charge density is very small.

bmim $^{+}$should be further decreased. However, the charge density of $\mathrm{I}^{-}$will be too low to have interaction with $\mathrm{MeOH}$.

\section{Conclusion}

For bmimCl, bmim ${ }^{+}$is not much solvated by $\mathrm{MeOH}$, but forms ion-pair clusters efficiently (Fig. 4a). On the other hand, for bmimBr and bmimI, the formation of ion-pair clusters is decreased, and the solvation for $\mathrm{bmim}^{+}$is obviously increased. Therefore, the solvation for $\mathrm{bmim}^{+}$is also controlled by the balance of interactions between bmim $^{+}$-anion and bmim $^{+}-\mathrm{MeOH}$. This complementary relation between ion-counterion and ionsolvent interaction was also observed in lithium halide-methanol solutions. The number of methanol molecules around $\mathrm{Li}^{+}$, especially in $\mathrm{Li}^{+}\left(\mathrm{Li}^{+} \mathrm{X}^{-}\right)_{\mathrm{m}}(\mathrm{MeOH})_{\mathrm{n}}$ clusters, increased with changing the anions from $\mathrm{Cl}^{-}$to $\mathrm{I}^{-} .^{21}$ Ion-pairs and solvated clusters of bmim ${ }^{+}$was fewer than those of $\mathrm{Li}^{+}$. The low charge density of bmim $^{+}$would decrease in clustering of bmim $^{+}$. The weak interaction of the bmim $^{+}$with the counterion will correlate with low melting point of the bmim ${ }^{+}$salt

\section{Acknowledgements}

This research was supported by JSPS, Grant-in-Aid for Encouragement of Scientists (18920015, 2004), (18920015, 2006 - 2007), and Scientific Research (B) (16350025, 2004 2006), by Steel Industry Foundation for the Advancement of Environmental Protection Technology, by Iketani Science and Technology Foundation, and by Hayashi Memorial Foundation for Female Natural Scientists.

\section{References}

1. J. D. Holbrey, W. M. Reichert, M. Nieuwenhuyzen, S. Johnston, K. R. Seddon, and R. D. Rogers, Chem. Commun., 2003, 1636.

2. H. Katayanagi, S. Hayashi, H. Hamaguchi, and K. Nishikawa, Chem. Phys. Lett., 2004, 392, 460.

3. J. Fuller, R. T. Carlin, H. C. De Long, and D. Haworth, J. Chem. Soc., Chem. Commun., 1994, 299.

4. J. Dupont, P. A. Z. Suarez, R. F. De Souza, R. A. Burrow, and J.-P. Kintzinger, Chem.-Eur. J., 2000, 6, 2377.

5. U. Schröder, J. D. Wadhawan, R. G. Compton, F. Marken, P. A. Z. Suarez, C. S. Consorti, R. F. De Souza, and J. Dupont, New J. Chem., 2000, 24, 1009.

6. M. Deetlefs, C. Hardacre, M. Nieuwenhuyzen, A. A. H. Padua, O. Sheppard, and A. K. Soper, J. Phys. Chem. B, 2006, 110, 12055.

7. Z. B. Alfassi, R. E. Huie, B. L. Milman, and P. Neta, Anal. Bioanal. Chem., 2003, 377, 159.

8. F. C. Gozzo, L. S. Santos, R. Augusti, C. S. Consorti, J. Dupont, and M. N. Eberlin, Chem.-Eur. J., 2004, 10, 6187.

9. P. J. Dyson, I. Khalaila, S. Luettgen, J. S. McIndoe, and D. Zhao, Chem. Commun., 2004, 2204.

10. G. P. Jackson and D. C. Duckworth, Chem. Commun., 2004, 522.

11. R. Bini, O. Bortolini, C. Chiappe, D. Pieraccini, and T. Siciliano, J. Phys. Chem. B, 2007, 111, 598.

12. T. Welton, Chem Rev., 1999, 99, 2071.

13. M. J. Earle, P. B. McCormac, and K. R. Seddon, Green Chem., 1999, 23.

14. T. Fischer, A. Sethi, T. Welton, and J. Woolf, Tetrahedron Lett., 1999, 40, 793.

15. K. Nobuoka, S. Kitaoka, K. Kunimitsu, M. Iio, T. Harran, W. Akihiro, and Y. Ishikawa, J. Org. Chem., 2005, 70, 10106.

16. A. C. Cole, J. L. Jensen, I. Ntai, K. L. T. Tran, K. J, Weaver, D. C. Forbes, and J. H. Davis, Jr., J. Am. Chem. Soc., 2002, $124,5962$.

17. C. J. Mathews, P. J. Smith, and T. Welton, Chem. Commun., 2000, 1249 .

18. D. Zhao, Z. Fei, T. J. Geldbach, R. Scopelliti, and P. J. Dyson, J. Am. Chem. Soc., 2004, 126, 15876.

19. A. Wakisaka, Faraday Discuss., 2007, 136, 299.

20. A. Wakisaka and Y. Watanabe, J. Phys. Chem. B, 2002, 106, 899.

21. T. Megyes, T. Radnai, and A. Wakisaka, J. Phys. Chem. A, 2002, 106, 8059 .

22. S. Mochizuki and A. Wakisaka, J. Phys. Chem. A, 2002, 106, 5095 .

23. P. Bonhote, A.-P. Dias, N. Papageorgiou, K. Kalyanasundaram, and M. Grätzel, Inorg. Chem., 1996, 35 , 1168.

24. J. G. Huddleston, A. E. Visser, W. M. Reichert, H. D. Willauer, G. A. Broker, and R. D. Rogers, Green Chem., 2001, 3, 156 . 